\title{
Infection Efficiency of Venturia inaequalis Ascospores as Affected by Apple Flower Bud Developmental Stage
}

\author{
S. Sanogo and D. E. Aylor, Department of Plant Pathology and Ecology, The Connecticut Agricultural Experiment \\ Station, P.O. Box 1106, New Haven 06504
}

\begin{abstract}
Sanogo, S., and Aylor, D. E. 1997. Infection efficiency of Venturia inaequalis ascospores as affected by apple flower bud developmental stage. Plant Dis. 81:661-663.

The average infection efficiency of ascospores of Venturia inaequalis deposited on cluster leaves of apple flower buds was 6 to $16 \%, 3$ to $9 \%$, and 0.4 to $0.6 \%$ at tight cluster, first pink, and full pink-to-bloom, respectively. No lesions were observed on flower bud cluster leaves at petal fall. However, the leaves on the vegetative shoot emerging from the flower bud were highly susceptible; the average infection efficiency of ascospores on these leaves was 6 to $21 \%$. The infection efficiency was more variable on young cluster and vegetative shoot leaves than on developing and mature cluster leaves. Results from this study indicate that differences in infection efficiency of $V$. inaequalis ascospores could be identified by apple bud growth stages.
\end{abstract}

Apple scab, caused by Venturia inaequalis (Cooke) G. Wint., is one of the most serious diseases of apple (Malus $\times$ domestica Borkh.) worldwide. Management of this disease relies heavily on the use of fungicides and could be improved if the probability of scab infection were known. In addition to temperature and moisture requirements for infection, taking into consideration factors such as inoculum levels and efficiency should increase the accuracy in prediction of scab infection. Aylor and Kiyomoto (3) indicated that the probability of scab infection could be estimated based on knowledge of the aerial spore concentration, deposition, and infection efficiency of ascospores on apple leaves. Susceptibility of apple leaves and fruit to scab generally decreases with the age of the tissue $(1,3,8,9)$; however, little is known about the susceptibility of apple floral parts to scab infection (6). Floral buds are the plant parts exposed first to infection by ascospores of $V$. inaequalis and assessing their susceptibility could contribute to improved prediction of primary scab infection. This study examined the effect of flower bud developmental stage on the infection efficiency of $V$. inaequalis ascospores.

\section{MATERIALS AND METHODS}

Plant production and assessment of flower bud leaf area. Three to five apple trees (cv. Marshall McIntosh on M.9 rootstock) were removed from cold storage and

Corresponding author: D. E. Aylor
E-mail: donaylor@caes.state.ct.us

Accepted for publication 28 February 1997.

Publication no. D-1997-0328-04R

(C) 1997 The American Phytopathological Society planted as needed. Each tree was potted in a mixture of ProMix BX (Premier Brands, New Rochelle, NY), sand, and perlite (2:1:1, $\mathrm{vol} / \mathrm{vol}$ ) and maintained in a greenhouse until the desired flower bud stage was reached.

Development of an apple flower bud encompasses several stages from dormancy to fruit set (5). Leaves from floral buds are formed as a rosette and are known as cluster leaves. From the flower bud, a vegetative shoot emerges, starting at about petal fall. The area of cluster leaves was determined by the following regression equation: $A=0.024+0.75 \times L \times W\left(R^{2}=0.98\right)$, in which $A$ is the leaf area measured by a Delta area meter (Delta-T Devices, Cambridge) interfaced to a television camera (model ITC 48, Ikegami Tsushinki Co. Ltd., Tokyo) and a picture monitor (model PM 930, Ikegami Tsushinki) and $L$ and $W$ are the length and width of leaves, respectively. Area measurements of 110 leaves collected from floral buds at stages from tight cluster to petal fall on greenhouse-grown apple trees provided the data used in the development of this regression equation. The area of leaves on the vegetative shoot was determined by the following regression equation developed in previous work (3): $A=$ $-0.35+0.74 \times L \times W$, in which $A, L$, and $W$ are as defined in the equation for cluster leaf area.

Inoculum, inoculation of apple flower buds, and assessment of infection efficiency. Ascospore inoculum was obtained from infected apple leaves collected from an orchard in 1995 and 1996 at the Lockwood farm in Hamden, CT. The leaves were dried and maintained in a cold room at $5^{\circ} \mathrm{C}$ until needed. Ascospores were extracted from 50 leaves by rinsing the leaves in tap water to remove surface dirt and by soaking the leaves for $45 \mathrm{~min}$ in 1.5 liter of distilled water in a plastic pan at room temperature
(19 to $21^{\circ} \mathrm{C}$ ). The pan was agitated every 2 min to facilitate release of ascospores from the leaves. The ascospore suspension was filtered twice through two layers of Miracloth (Chicopee Mills, Milltown, NJ). A $300-\mathrm{ml}$ aliquot of the filtrate was centrifuged for $15 \mathrm{~min}$. The supernatant was discarded, and the pellet was resuspended in 15 to $20 \mathrm{ml}$ of distilled water. The concentration of ascospores in the final suspension was estimated with a hemacytometer.

Inoculation of flower buds at each developmental stage was performed as described by Aylor and Kiyomoto (3). Basically, cluster and vegetative shoot leaves were sprayed with the ascospore suspension with a handheld sprayer. Cardboard masks were used around the buds being inoculated to prevent inoculum drift among buds. The density of ascospores deposited on each bud was estimated from counts made on a microscope slide coverslip placed next to each bud at the time of inoculation and held at the approximate angle of leaf tissue in the bud. Some buds were left unsprayed on each tree to serve as controls.

To assess the germinability of ascospores during each inoculation episode, $2 \%$ water agar medium in 9-cm petri dishes was sprayed with the ascospore suspension and incubated at $20^{\circ} \mathrm{C}$ (1). The percentage of germinated ascospores was determined after $18 \mathrm{~h}$ of incubation (4) by examining 40 to 60 ascospores selected arbitrarily.

The trees were placed in a dew chamber at $20^{\circ} \mathrm{C}$ for $24 \mathrm{~h}$ to promote bud infection. They subsequently were placed in a growth chamber at 18 to $22^{\circ} \mathrm{C}$ with $12 \mathrm{~h} / 12 \mathrm{~h}$ light/ dark until lesions developed, which took about 14 to 21 days. The number of sporulating lesions was recorded for each bud. Chlorotic spots that revealed signs of scab upon placement of bud leaves in a highhumidity chamber also were included in the sporulating lesions count.

The infection efficiency, $I E$, was assessed as $I E=(L S / G) \times 100$, in which $L S$ is the number of lesions formed per leaf area at the time of inoculation and $G$ is the number of deposited germinable ascospores per unit of leaf area. The density of germinable ascospores, $G$, was determined as $G=N \times$ $P g$, in which $N$ is the density of deposited ascospores, and $P g$ is the proportion of ascospores that germinated on $2 \%$ water agar medium.

Treatments, experimental design, and data analysis. The treatments consisted of four stages of flower bud development: tight 
cluster (TC), first pink (FP), full pink-tovidual buds at a given stage were considered as experimental units. A series of 11 inoculations was performed, using part or all of the four treatments. Two to three trees were used on each inoculation occasion to provide at least five buds (replications) per treatment. Because the germinable ascospore density, $G$, varied across the 11 inoculation events, the data collected over all inoculation episodes were categorized into homogeneous groups according to three ranges of $G$. In the first group, $G$ was between 2 and 5 (average of 3 ascospores per $\mathrm{cm}^{2}$ ), and the treatments included were FP and PF. In the second group, $G$ was between 7 and 15 (average of 10 ascospores per $\mathrm{cm}^{2}$ ), and the treatments were TC, PF, FFB, and PF. In the third group, $G$ was between 16 and 25 (average of 21 ascospores per $\mathrm{cm}^{2}$ ), and the treatments were TC, FP, and FFB. The germination of ascospores on $2 \%$ water agar medium was 70 to $91 \%$ in the first group, 30 to $91 \%$ in the second group, and 34 to $87 \%$ in the third group. Within each group, a $t$ test or an analysis of variance was used to assess the effect of floral bud stage on infection efficiency. After analysis of variance, means were separated by confidence levels at $P=$ 0.05 . All analyses were performed with Minitab statistical analysis software (Minitab, Inc., State College, PA).

\section{RESULTS AND DISCUSSION}

No lesions were observed on control buds left unsprayed across all inoculation events. The infection efficiency of ascospores was similar among young leaves and was in the range of 5 to $21 \%$ regardless of whether the leaves were cluster or vegetative shoot leaves. On cluster leaves at stages of FP, $\mathrm{FFB}$, and PF, the infection efficiency was 3 to $9 \%, 0.4$ to $0.6 \%$, and $0 \%$, respectively. (Table 1) These results suggest that as the leaves from the flower bud aged, they bebloom (FFB), and petal fall (PF). Indi-

came less susceptible to infection by ascospores. Qualitatively, similar results were reported by Falk et al. (6) who assessed susceptibility of flower buds on a 0 to 1 scale; values for relative susceptibility were $1,1,0.7,0.4,0.2$, and 0.1 at green tip, $2-\mathrm{cm}$ green, tight cluster, pink, bloom, and petal fall, respectively.

Decreasing susceptibility with age also has been shown for leaves of vegetative buds and fruit of apple. Anagnostakis and Aylor (1) found that the average lesion-causing efficiencies of ascospores on apple leaves at three early stages of leaf expansion with average leaf areas of $1.23,2.88$, and $4.4 \mathrm{~cm}^{2}$ were 5, 6, and $14 \%$, respectively. Similarly, Aylor and Kiyomoto (3) observed that the lesion-causing efficiency of ascospores decreased from 23 to $1 \%$ on expanding apple leaves with leaf areas ranging from 9.8 to $27.7 \mathrm{~cm}^{2}$. Using ascospores and conidia of $V$. inaequalis, Schwabe (8) inoculated apple leaves at different stages of expansion; leaves on trees receiving balanced nutrient solution became more resistant to infection with increasing age and reached complete resistance at the time leaf expansion ceased at about 12 to 13 days after unfolding. On developing apple fruit, Schwabe et al. (9) found that longer continuous wet periods were necessary for infection by conidia of $V$. inaequalis and concluded that susceptibility to scab infection decreases with fruit age.

It is unclear what contributed to the difference in infection efficiency in response to an increase in germinable ascospore density. It is possible that age-related factors could account, in part, for the observed difference. The cluster leaves are not identical in age or development, although they appear so because of almost nonexistent internodes. Similarly, the leaves on the developing vegetative shoot are not homogenous with respect to age. Perhaps ontogenic resistance is highly variable among these leaves (cluster and vegetative shoot) when they

Table 1. Infection efficiency (IE) of ascospores of Venturia inaequalis on cluster and vegetative shoot leaves at various apple flower bud developmental stages

\begin{tabular}{|c|c|c|c|c|c|c|c|c|}
\hline \multirow[b]{3}{*}{$\begin{array}{l}\text { Bud } \\
\text { stage }^{w}\end{array}$} & \multicolumn{6}{|c|}{ Average germinable ascospore density $\left(\mathrm{no} / \mathrm{cm}^{2}\right)$} & & \\
\hline & \multicolumn{2}{|c|}{$3(0.17)^{x}$} & \multicolumn{2}{|c|}{$10(0.35)$} & \multicolumn{2}{|c|}{$21(0.53)$} & \multicolumn{2}{|c|}{ All inoculations } \\
\hline & $\begin{array}{l}\text { Cluster } \\
\text { leaves }^{y}\end{array}$ & $\begin{array}{l}\text { Shoot } \\
\text { leaves }\end{array}$ & $\begin{array}{l}\text { Cluster } \\
\text { leaves }\end{array}$ & $\begin{array}{l}\text { Shoot } \\
\text { leaves }\end{array}$ & $\begin{array}{l}\text { Cluster } \\
\text { leaves }\end{array}$ & $\begin{array}{l}\text { Shoot } \\
\text { leaves }\end{array}$ & $\begin{array}{l}\text { Cluster } \\
\text { leaves }\end{array}$ & $\begin{array}{l}\text { Shoot } \\
\text { leaves }\end{array}$ \\
\hline $\mathrm{TC}$ & $\ldots^{\mathrm{z}}$ & $\ldots$ & $\begin{array}{l}16 \mathrm{Aa} \\
(2.7)\end{array}$ & $\ldots$ & $\begin{array}{c}6 \mathrm{Ba} \\
(1.4)\end{array}$ & $\ldots$ & $\begin{array}{l}12 \mathrm{a} \\
(2.1)\end{array}$ & $\cdots$ \\
\hline FP & $\begin{array}{l}5 \mathrm{Aa} \\
(0.9)\end{array}$ & $\cdots$ & $\begin{array}{l}9 \mathrm{Bb} \\
(4.6)\end{array}$ & $\ldots$ & $\begin{array}{l}3 \mathrm{Aa} \\
(1)\end{array}$ & .. & $\begin{array}{c}5 \mathrm{~b} \\
(1.2)\end{array}$ & $\cdots$ \\
\hline FFB & $\ldots$ & $\ldots$ & $\begin{array}{l}0.6 \mathrm{Ac} \\
(0.12)\end{array}$ & $\ldots$ & $\begin{array}{l}0.4 \mathrm{Ab} \\
(0.07)\end{array}$ & $\ldots$ & $\begin{array}{c}0.5 \mathrm{c} \\
(0.07)\end{array}$ & $\cdots$ \\
\hline PF & $0 \mathrm{~b}$ & $\begin{array}{r}21 \mathrm{~A} \\
(3.4)\end{array}$ & $0 \mathrm{c}$ & $\begin{array}{c}6 \mathrm{~B} \\
(0.9)\end{array}$ & & $\ldots$ & $0 \mathrm{c}$ & $\begin{array}{l}13 \\
(2.3)\end{array}$ \\
\hline
\end{tabular}

${ }^{\mathrm{w}} \mathrm{TC}=$ tight cluster; $\mathrm{FP}=$ first pink; FFB = full pink-to-bloom; and PF = petal fall. The stages were identified according to Childers (5).

${ }^{\mathrm{x}}$ Numbers in parentheses are standard errors of the mean.

${ }^{y}$ For each stage, $I E$ is compared across average germinable ascospore density $(G)$ with uppercase letters, and for each level of $G, I E$ is compared across stage with lowercase letters. Numbers with the same letters are not significantly different according to confidence levels at $P=0.05$.

z Treatment not available at this level of $G$. are young but is expressed more uniformly among leaves as they develop and mature.

The use of the term infection efficiency entails an assessment of infections per unit area. In this study, we actually assessed the number of lesions per unit area of leaf, which is a reasonable measure of infection efficiency because a very susceptible cultivar (Marshall McIntosh) was used and maintained after inoculation under optimum conditions for infection and lesion development. However, it cannot be assumed that the leaves hardened-off and matured at each bud stage similarly to leaves on trees in an orchard. Thus, it is possible that the infection efficiency on leaves at the different bud stages may be different in an orchard. Additionally, although 14 to 21 days was sufficient to observe lesions on young leaves, it cannot be assumed that this incubation period was long enough for infections to be expressed on cluster leaves at later stages of development.

The results from this study are relevant to apple scab management. As indicated by MacHardy (7), knowing how much scab is expected to develop from a given infection period provides helpful information in fungicide application decision making. Scab levels expected at various phenological stages could be derived from a knowledge of inoculum level and infection efficiency on apple tissue as investigated in the current study.

A cornerstone of apple scab management is the minimization of primary infection of apple tissue by ascospores of $V$. inaequalis. The data from this study show that for calculations of risk in an epidemiological model, cluster leaves probably can be omitted as susceptible tissue for primary infection at petal fall, given the low inoculum in a commercial orchard (2) and the low infection efficiency at that bud stage. This seems a reasonable hypothesis with spur-type trees on which few vegetative shoots emerge from flower buds. However, the fruit, and with terminal-type trees the developing vegetative shoots, continue to provide additional tissue that is very susceptible to scab.

\section{ACKNOWLEDGMENTS}

This study was based on work supported in part by the Cooperative State Research, Education, and Extension Service, U.S. Department of Agriculture (Agreement 93-37303-9134). We thank P. Thiel and M. DeVito for technical assistance and F. J. Ferrandino for many critical reviews of the manuscript.

\section{LITERATURE CITED}

1. Anagnostakis, S. L., and Aylor, D. E. 1991. Efficiency of ascospores of Venturia inaequalis in producing scab lesions on apple leaves. Plant Dis. 75:918-920.

2. Aylor, D. E. 1996. Comparison of the seasonal pattern of airborne Venturia inaequalis ascospores with the release potential of $V$. inaequalis ascospores from a source. Phytopathology 86:769-776.

3. Aylor, D. E., and Kiyomoto, R. K. 1993. Relationship between aerial concentration of Venturia inaequalis ascospores and development of apple scab. Agric. For. Meteorol. 63:133-147.

4. Biggs, A. R., and Warner, J. 1987. Control of 
primary and secondary apple scab infections with sterol-inhibiting fungicides. Can. J. Plant Pathol. 9:41-48.

5. Childers, N. F. 1983. Modern Fruit Science. Horticultural Publications, Gainesville, FL.

6. Falk, S. P., Gadoury, D. M., and Seem, R. C. 1995.
Analysis of risk of primary apple scab infection. (Abstr.) Phytopathology 85:1556.

7. MacHardy, W. E. 1996. Apple Scab: Biology, Epidemiology, and Management. The American Phytopathological Society, St. Paul, MN.

8. Schwabe, W. F. S. 1979. Changes in the sus- ceptibility of apple leaves as influenced by age. Phytophylactica 11:53-56.

9. Schwabe, W. F. S., Jones, A. L., and Jonker, J. P. 1984. Changes in the susceptibility of developing apple fruit to Venturia inaequalis. Phytopathology 74:118-121. 